\title{
ACCESSING ANALYSIS OF PASSENGERS COVERED BY PAYMENT KIOSKS: A CASE FOR THE GAZIANTEP PUBLIC TRANSPORTATION SYSTEM
}

\author{
Eren ÖZCEYLAN ${ }^{1 *}$, Barış ÖZKAN² \\ ${ }^{1}$ Gaziantep University, Faculty of Engineering, Department of Industrial Engineering, 27310, Gaziantep, \\ Turkey \\ ${ }^{2}$ Ondokuz Mayis University, Faculty of Engineering, Department of Industrial Engineering, 55139, Samsun, \\ Turkey
}

Received: April 19, 2019; Accepted: June 13, 2019; Published: July 01, 2019

\begin{abstract}
Recently, the use of public transport has become widespread with the increasing population. This brings with it many problems. Since the points of payment kiosks are not regularly distributed where the population is concentrated, the most important problem is accessing to these kiosks. The accessing analysis of passengers covered by payment kiosks in Gaziantep, Turkey is considered in this study. 177 different locations which have the densest population are considered as the demand points and 379 payment kiosks are considered as the source points. All spatial data are obtained using a geographic information system (GIS). The goal of this study is to maximize the rate of passengers (demand points) who try to access to the payment kiosks. To do so, two different location-allocation analysis which are set covering and p-median models were applied using mathematical modeling approach. As a result, the required number of kiosks and coverage distances were determined to satisfy all demand.
\end{abstract}

Keywords: Case study, Geographic information system, P-median problem, Public transportation, Set covering

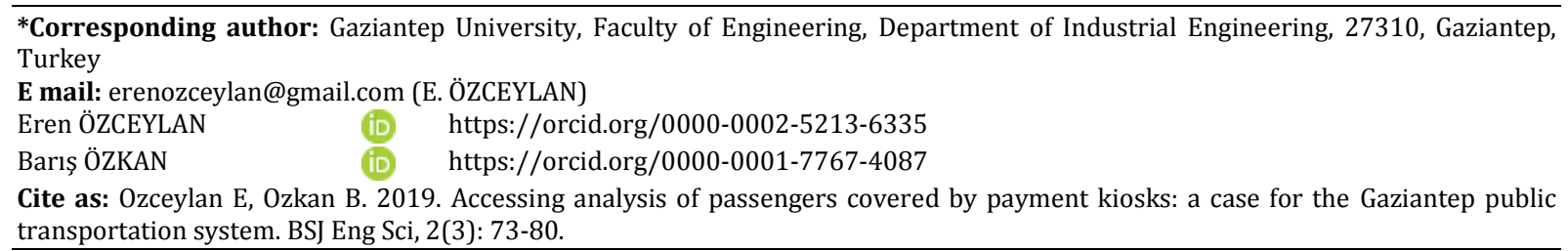

\section{Introduction}

Continuous expansion of the cities, development of multicenter urban structure and changes in population density has affected the traffic and increased congestion. For that reason, the urban transportation has been one of the most important problems of big cities in developing countries. Public transportation is one of the solution approaches to decrease the negative effects of traffic. In big cities of the world, public transport constitutes $50 \%$ of urban travel (Koryagin, 2018). For many years, the use of an electronic smart card as an alternative means for users to access and pay for transport services is a viable option. For that reason, the mutual influence between the passengers and ancillary items such as payment machines or kiosks in the urban transport system becomes more significant. To gain the maximum benefit from this system, the placement of transportation tools and guiding urban travels towards 
them has found a crucial role in decreasing traffic problems. Analyzing the geographic locations of ticket machines or kiosks and their accessibility are directly deal with location and allocation problems. Research on urban transportation literature spreads on a large area. While some of the researchers discuss the passengers' behavior in urban transportation (Choi et al., 2013; Brette et al., 2014), some of them investigate the environmental effects (He et al., 2011; Cheng et al., 2015) and optimization of the transportation network systems (Pu and Ma, 2014; Balabanov et al., 2016).

The paper of Van Oudheusden et al. (1987) which is one of the earliest studies in literature applied set covering model to solve the practical problem of bus route network design. Possible bus routes are identified with facilities, which can be located, and zones in the urban area are identified with customers who will be allocated to the established facilities. Then, Murray (2001) addressed strategic aspects of public transport in Brisbane, Australia using a commercial GIS integrated with various spatial analytical techniques including a location covering model. As a sharing transportation system problem, Amoroso et al. (2015) proposed a study to find the best location for the bicycle lots in the old town of Palermo. The optimization method includes the use of both a set covering model and a maximum coverage location problem. Feng et al. (2016) proposed a setting method of passenger sites on inter-city expressway to facilitate residents travel along inter-city expressway. Optimization model was established with the target of minimizing total walking distance to determine the best place of each passenger site corresponding with settlement set. Finally, Mete et al. (2018) applied five different locationallocation models such as set covering, $p$-median and pcenter in order to find possible locations of the bike sharing stations for university students. The purpose is to minimize the total walking distance in a campus. In addition to the aforementioned existing studies, the reader is referred to Farahani et al. (2018) for an excellent review of the operations research models in urban service facility location.

When the existing studies are investigated, it is clear to see that there is still a gap to be filled on location and allocation of payment machines or kiosks mathematically. In view of this, current locations of smart card kiosks in Gaziantep, Turkey are investigated to provide optimal distribution for the passengers. To do so, a two-step approach is followed. First, geographic information of 379 kiosks as source node and 177 neighborhoods as demand node are gathered using GIS. Secondly, P-median and set covering models are applied.

\section{Location-Allocation Models}

Spatial distribution of the ticket machines or kiosks is an important issue in public transportation systems to increase the accessibility. Thus, in this section, the location-allocation models used in this study to ensure the optimal distribution of the ticket kiosks were described.

\subsection{Set covering problem}

$G(N, A)$ is a fully connected network and $N$ is the set of nodes while $A$ is set of edges between these nodes ( $A=$ $\{(i, j) \mid i \neq j$ and $i, j \in N\}$ ). $N$ consists of nodes, $I$ consists of demand nodes (passengers) and $K$ consists of source nodes (kiosks). There are distances identified as $d_{i k}$ between all node pairs within the network. The set covering problem is identified as a facility location selection problem in a way to reach every cluster at least once in a predetermined time on this network. The formulation of the set covering problem as follows (Beasley, 1987):

Decision variable

$y_{k}=\left\{\begin{array}{c}1, \text { if potential kiosk } k \text { is opened }(\forall k \in K) \\ 0, \text { otherwise }\end{array}\right.$

Objective function

$\operatorname{Min} Z=\sum_{k \in K} y_{k}$

s.t.

$\sum_{k \in K} a_{i k} y_{k} \geq 1 \quad \forall i \in I$

$y_{k} \in\{0,1\}$

$\forall k \in K$

The objective function (1) is to minimize the number of source nodes (kiosks) to be opened. Constraint (2) is to provide a service from at least one opened kiosk to all passengers within the predetermined time or distance. Constraint (3) is the sign constraint of the decision variable. Here, $a_{i k}$ is a parameter:

$a_{i k}=\left\{\begin{array}{l}1, \text { if can be reached from } \mathrm{k} \text { potential kiosk to i passenger } \\ \quad \text { in a predetermined timek }\left(\forall_{\mathrm{i}} \in \mathrm{I}, \forall_{\mathrm{k}} \in \mathrm{K}\right) \\ 0, \text { otherwise }\end{array}\right.$

\subsection{P-median problem}

In addition to the model in sub-section 3.1, the P-median problem tries to determine $P$ amount candidate facility (kiosks) that is scheduled to open and which passengers will be assigned to each kiosk (Mladenović et al., 2003). The formulation of the P-median problem is given as follows (Teixeira and Antunes, 2008):

Decision variable

$x_{i k}=\left\{\begin{array}{l}1, \text { if passenger } \mathrm{i} \text { is assigned to potential kiosk } \\ \quad \mathrm{k}\left(\forall_{\mathrm{i}} \in \mathrm{I}, \forall_{\mathrm{k}} \in \mathrm{K}\right) \\ 0, \text { otherwise }\end{array}\right.$ 
Objective function

$\operatorname{Min} Z=\sum_{i \in I} \sum_{k \in K} d_{i k} x_{i k}$

s.t.

$\sum_{k \in K} x_{i k}=1 \quad \forall i \in I$

$x_{i k} \leq y_{k} \quad \forall i \in I, \forall k \in K$

$\sum_{k \in K} y_{k}=P$

$y_{k}, x_{i k} \in\{0,1\} \quad \forall i \in I, \forall k \in K$

The objective function (4) is to minimize the total travelled distance between passengers and kiosks. Constraint (5) provides the assignment of each passenger to a kiosk. While constraint (6) provides the assignment of passengers to the opened kiosks, constraint (7) helps us to determine a limit for the number of kiosks which should be opened. Constraint (8) is the sign constraint of the decision variables.

\section{Location-Allocation Models}

In this section, the current locations of kiosks in the province of Gaziantep were examined. Their accessibility and spatial distributions were discussed using mathematical models described in the previous section.

\subsection{Set covering problem}

This section presents the results of implementing the mathematical models on a city-wide area. The study area, Gaziantep, is the $8^{\text {th }}$ most crowded city of Turkey. The city has a mean elevation of 814 meters, and in 2018, its population was 2,005,515 with a total acreage of 7,642 $\mathrm{km}^{2}$. The city is an important commercial and industrial center for Turkey and is located at $37^{\circ} 04^{\prime}$ North, $37^{\circ} 23^{\prime}$ East (Figure 1). The city center of Gaziantep is considered as the study area.

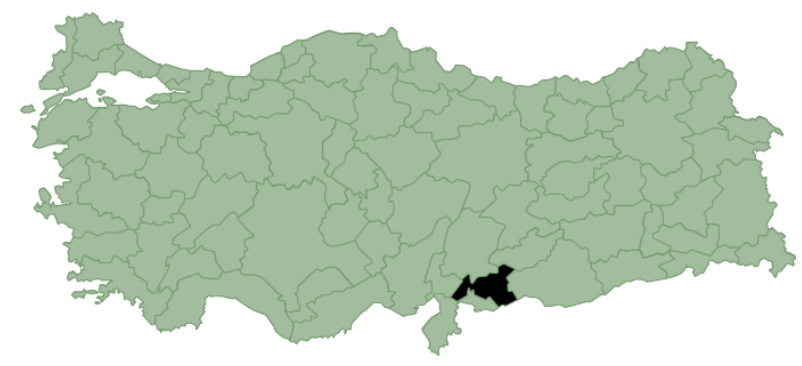

Figure 1. City of Gaziantep, Turkey.

In the city center of Gaziantep, the locations of 379 kiosks and 177 neighborhood points are determined with ESRI ArcGIS 10.2 software. Locations of 379 kiosks are recorded from the website (https://gaziantepkart.com.tr/) of Gaziantep Municipality. The locations of kiosks and neighborhood points are represented in Figure 2.

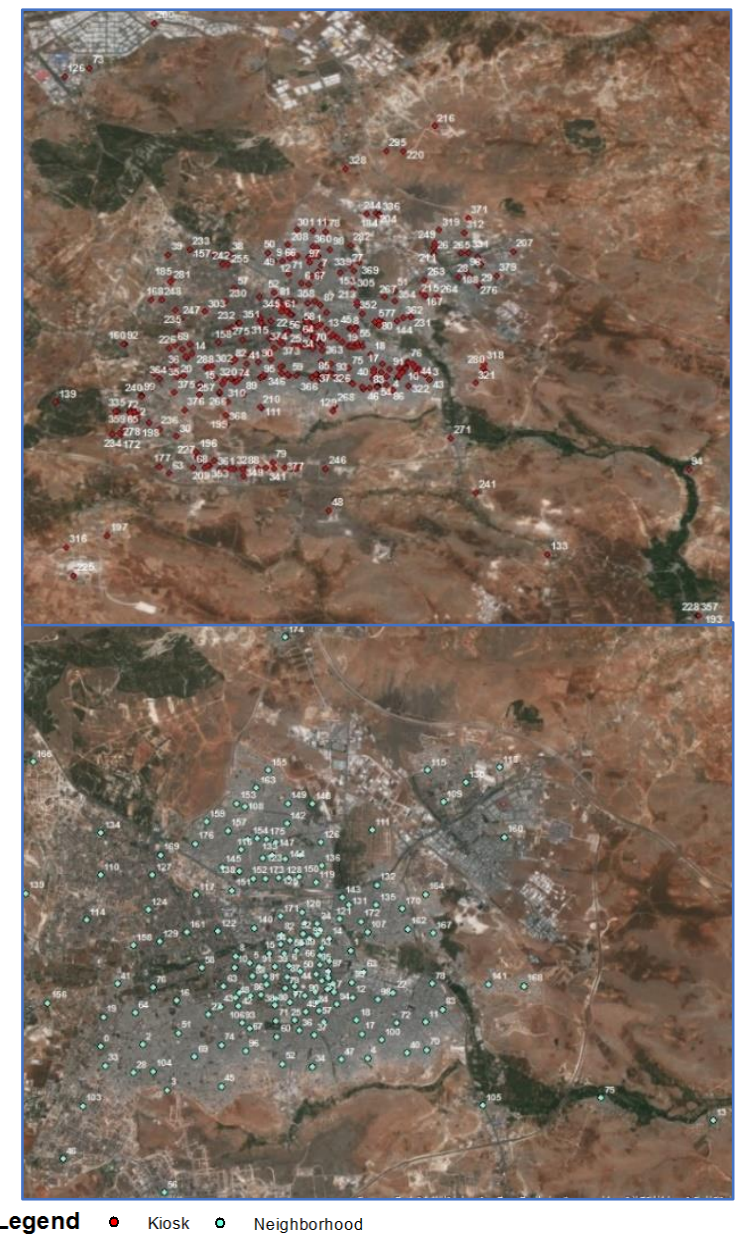

Figure 2. Locations of 379 kiosks (top) and 177 neighborhood nodes (bottom).

The geographical position of every node is defined by cartographic coordinates (longitude and latitude in meters). ESRI ArcGIS 10.2 software as a GIS was used to calculate the real distances between the facilities in the network. The road network is shown in Figure 3. The network distances between the all nodes are available upon request.

\subsection{Application of the location-allocation models}

In this section, previously described two mathematical models were applied to the given problem in the former section. In all mathematical models, kiosks are represented by $k$ and neighbourhood nodes are represented by $i$. We took all of runs on a server with 1.8 $\mathrm{GHz}$ Intel Core processor and $4 \mathrm{~GB}$ of RAM and the computation time required to solve the model optimality using the GAMS-CPLEX is less than $10 \mathrm{CPU}$ seconds.

\subsubsection{The result of set covering model}

The data, were obtained on the basis of GIS, are primarily solved with the set covering model to investigate the coverage ability of kiosks. To do so, 39 different coverage areas in the range of $713 \mathrm{~m}$ and $7.4 \mathrm{~km}$ were examined. While the opened kiosks under different coverage limits are given in Table 1, the relationship between number of kiosks and coverage limits is shown in Figure 4. 


\section{Black Sea Journal of Engineering and Science}

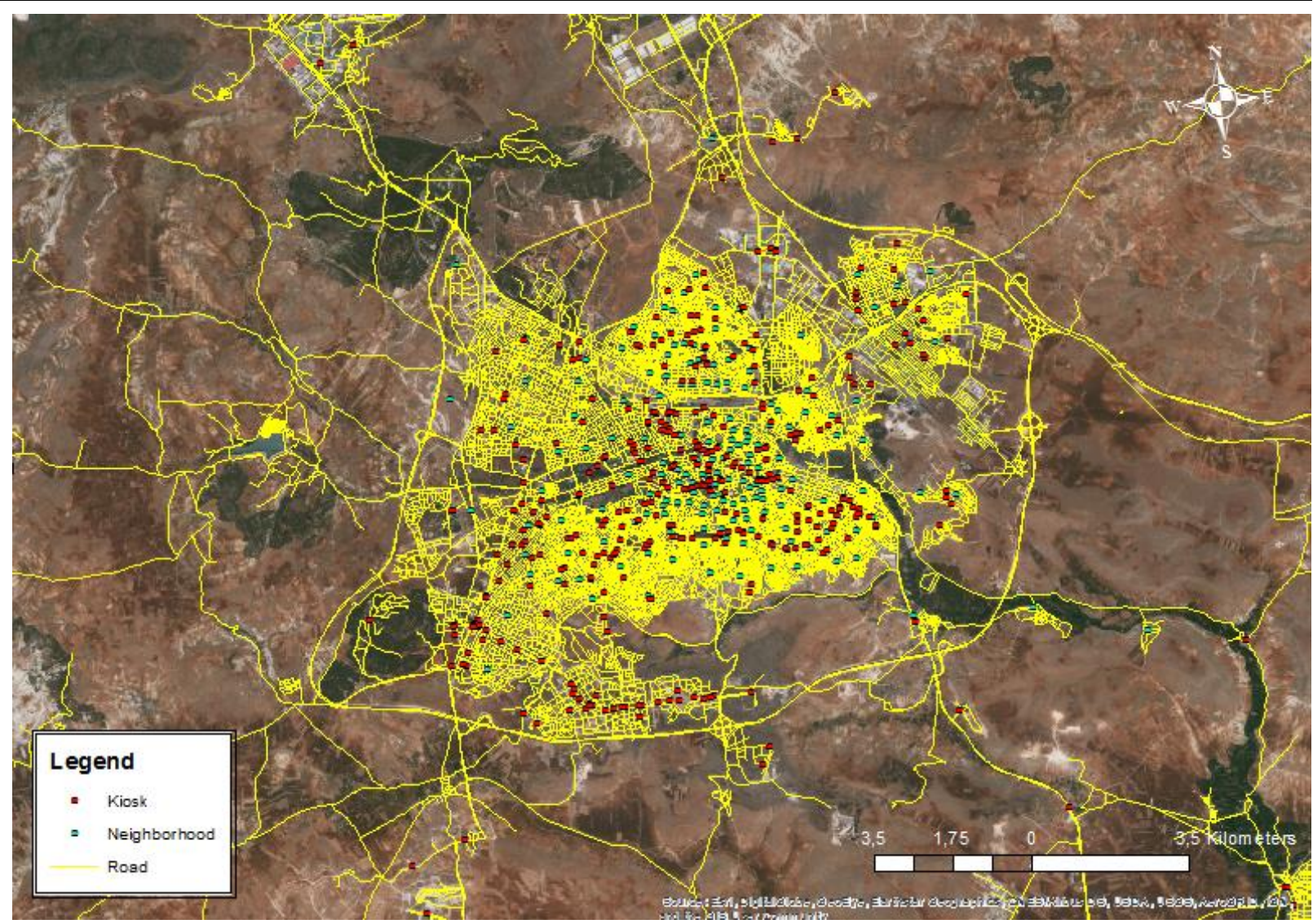

Figure 3. Road network of study area with all nodes.

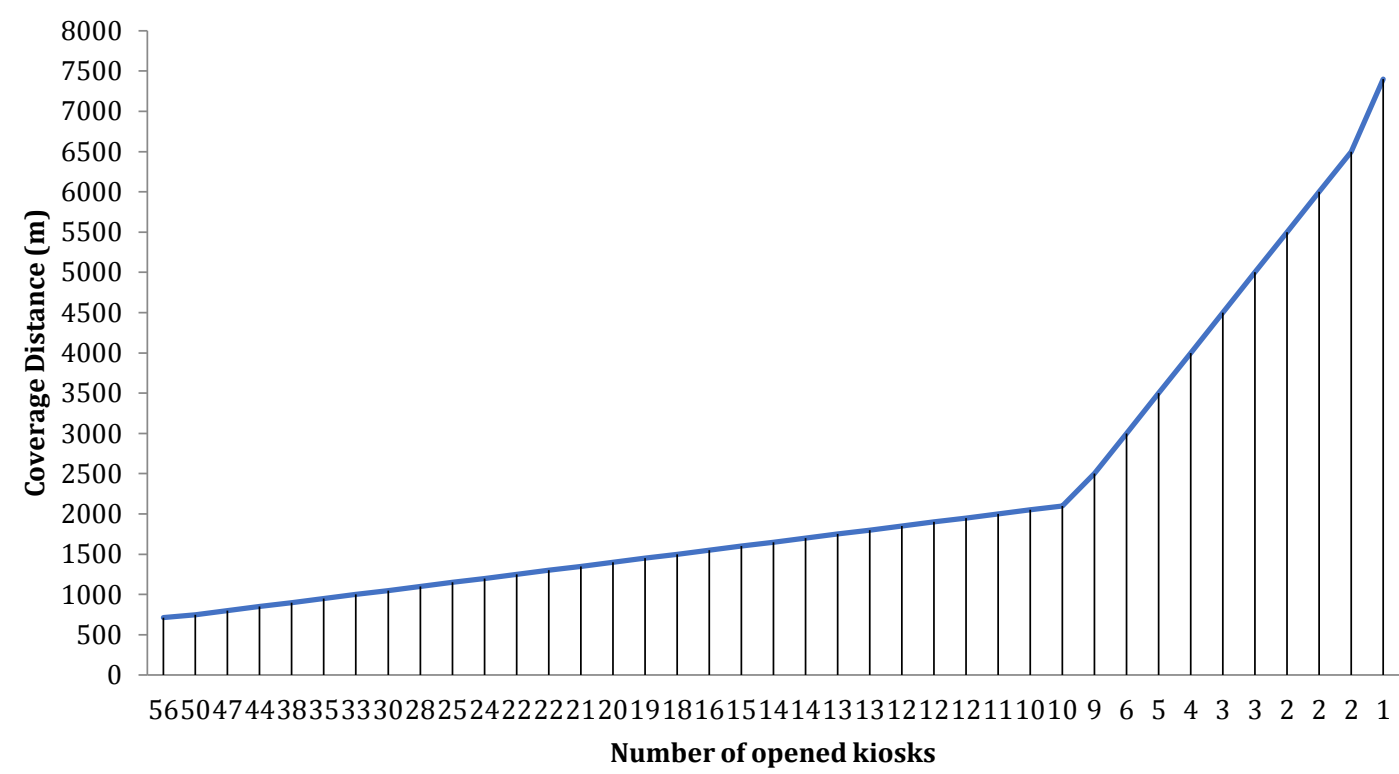

Figure 4. Coverage distance versus number of opened kiosks 
Table 1. Opened kiosks under the different coverage limits

\begin{tabular}{|c|c|c|c|c|c|}
\hline $\begin{array}{l}\text { Limit } \\
(\mathrm{m})\end{array}$ & Opened kiosks & $\begin{array}{c}\text { Limit } \\
(\mathrm{m})\end{array}$ & Opened kiosks & $\begin{array}{l}\text { Limit } \\
(\mathrm{m})\end{array}$ & Opened kiosks \\
\hline 713 & $\begin{array}{c}\text { 2-5-7-17-27-31-45-46-52-53-61-69-71-72-82-89-94- } \\
\text { 100-111-126-150-152-155-160-169-179-184-185-187- } \\
\text { 188-191-195-197-202-204-206-209-211-213-226-228- } \\
249-261-262-273-282-330-335-338-343-352-355-356- \\
360-372-376\end{array}$ & 1350 & $\begin{array}{l}15-66-69-89-96-124- \\
148-169-190-200-202- \\
207-210-251-253-256- \\
291-321-335-351-352\end{array}$ & 2000 & $\begin{array}{l}44-139-160- \\
185-235-247- \\
248-262-323- \\
339-362\end{array}$ \\
\hline 750 & $\begin{array}{c}2-5-7-17-24-28-31-33-45-46-57-59-61-69-71-72-82-89- \\
90-102-106-148-150-152-167-174-185-186-187-188- \\
197-202-204-208-211-220-226-228-249-251-252-258- \\
273-330-335-339-362-364-369-376\end{array}$ & 1400 & $\begin{array}{l}15-52-61-69-72-89-99- \\
128-160-165-167-194- \\
202-234-252-253-254- \\
\quad 321-352-379\end{array}$ & 2050 & $\begin{array}{l}139-160-176- \\
185-209-235- \\
248-306-325- \\
\quad 332\end{array}$ \\
\hline 800 & $\begin{array}{c}\text { 4-5-14-17-24-31-33-38-45-46-59-61-69-82-89-100- } \\
\text { 101-107-117-119-148-150-152-167-174-185-186-187- } \\
\text { 188-197-204-205-211-228-229-244-249-306-317-322- } \\
324-325-330-335-341-352-376\end{array}$ & 1450 & $\begin{array}{l}37-51-52-65-99-142- \\
182-189-194-195-221- \\
228-230-238-252-258- \\
321-352-379\end{array}$ & 2100 & $\begin{array}{l}79-139-160- \\
185-202-235- \\
247-252-316- \\
325\end{array}$ \\
\hline 850 & $\begin{array}{c}2-5-13-14-24-27-31-46-52-57-59-69-82-89-102-107- \\
117-126-128-137-148-150-152-160-169-176-187-188- \\
196-197-204-211-228-231-244-249-259-306-317-321- \\
323-335-347-363\end{array}$ & 1500 & $\begin{array}{l}37-60-126-142-148-157- \\
174-177-191-195-201- \\
210-228-244-256-298- \\
321-333\end{array}$ & 2500 & $\begin{array}{l}102-173-182- \\
226-235-238- \\
282-335-357\end{array}$ \\
\hline 900 & $\begin{array}{c}\text { 2-4-5-18-57-61-63-65-69-71-72-77-92-112-126-148- } \\
\text { 176-187-188-196-197-202-228-238-246-280-291-294- } \\
\text { 300-306-307-321-333-335-346-360-363-370 }\end{array}$ & 1550 & $\begin{array}{l}37-52-59-120-128-142- \\
157-174-185-202-228- \\
235-324-352-376-379\end{array}$ & 3000 & $\begin{array}{l}38-93-99-152- \\
273-308\end{array}$ \\
\hline 950 & $\begin{array}{c}\text { 14- 24-30-36-57-59-65-73-84-91-110-126-143-147- } \\
\text { 148-155-166-169-174-177-182-187-198-211-212-220- } \\
230-273-280-300-321-345-357-370-373\end{array}$ & 1600 & $\begin{array}{l}14-15-52-156-182-185- \\
194-195-228-235-313- \\
322-346-349-355\end{array}$ & 3500 & $\begin{array}{l}2-18-66-212- \\
307\end{array}$ \\
\hline 1000 & $\begin{array}{c}2-4-21-24-30-36-49-59-65-68-112-123-128-147-152- \\
196-206-224-238-244-245-280-284-288-293-300-305- \\
321-322-357-358-364-373\end{array}$ & 1650 & $\begin{array}{l}41-59-70-78-139-154- \\
160-185-202-215-235- \\
271-273-359\end{array}$ & 4000 & $\begin{array}{l}176-249-313- \\
329\end{array}$ \\
\hline 1050 & $\begin{array}{c}21-24-26-62-65-66-69-94-96-98-104-108-112-120-147- \\
188-190-193-201-202-207-211-252-273-276-284-293- \\
320-321-345\end{array}$ & 1700 & $\begin{array}{l}52-70-73-127-152-174- \\
202-235-259-282-330- \\
\quad 349-367-372\end{array}$ & 4500 & $7-84-148$ \\
\hline 1100 & $\begin{array}{c}24-41-55-65-66-110-123-124-128-167-177-179-187- \\
189-195-200-201-202-203-205-228-246-261-293-321- \\
345-347-373\end{array}$ & 1750 & $\begin{array}{l}4-58-73-96-202-222- \\
235-259-267-335-339- \\
349-362\end{array}$ & 5000 & $187-206-236$ \\
\hline 1150 & $\begin{array}{l}\text { 35- 39-65-66-69-110-124-128-137-143-147-148-152- } \\
\text { 181-190-202-207-209-236-249-306-330-331-360-376 }\end{array}$ & 1800 & $\begin{array}{l}90-128-139-154-160- \\
185-186-235-241-248- \\
339-362-367\end{array}$ & 5500 & $154-282$ \\
\hline 1200 & $\begin{array}{c}31-52-54-55-65-66-112-116-123-124-147-152-157- \\
161-177-182-236-245-306-333-345-360-373-374\end{array}$ & 1850 & $\begin{array}{l}48-81-90-154-174-185- \\
187-228-235-248-312- \\
378\end{array}$ & 6000 & $154-284$ \\
\hline 1250 & $\begin{array}{c}37-52-58-61-65-92-110-124-157-165-182-190-200- \\
234-236-259-278-281-291-345-364-373\end{array}$ & 1900 & $\begin{array}{l}59-81-85-142-147-160- \\
185-187-202-235-249- \\
378\end{array}$ & 6500 & $46-254$ \\
\hline 1300 & $\begin{array}{c}61-65-99-112-124-126-133-147-148-165-170-181-182- \\
253-258-261-291-306-321-352-364-373\end{array}$ & 1950 & $\begin{array}{l}10-142-147-150-185- \\
188-235-244-247-350- \\
362-378\end{array}$ & 7400 & 25 \\
\hline
\end{tabular}

As expected, increasing the coverage limit (distance) decreases the number of kiosks which are opened. There is no feasible solution under the coverage limit which is less than $713 \mathrm{~m}$. It means that all passengers cannot reach to at least one kiosk in less than $713 \mathrm{~m}$ distance. The highest value of the coverage distance range is $7.4 \mathrm{~km}$. In other words, all passengers can reach to the 271st kiosk within a $7.4 \mathrm{~km}$ distance. Finally, increasing the number of kiosks from 1 to 56 leads a decrement in coverage limit by $90 \%$. Illustrations of 4 different set covering cases are shown in Figure 5. Not surprisingly, while the middlemost kiosk among others is opened in the first case (top-left in Figure 5), the geographical distribution of the opened kiosks was expanded in the last case (bottom-right in Figure 5).

\subsubsection{The result of $P$-median model}

In addition to the set covering model in previous section, P-median model was also implemented to allocate kiosks to the demand points (passengers). We implement the Pmedian model with different $p$ values by setting it from 1 to 379 . The results of P-median problem are shown in Figure 6. Figure 6 shows the total walked distance regarding to the number of opened kiosks $(p)$. It is clear to see that there is no improvement in the objective function after 135 kiosks. It means that the geographical distribution of 135 kiosks is enough to be accessed by all passengers. Figure 6 also says that decreasing the number of opened kiosks from 135 to 1 increases the total walking distance by $667 \%$. 


\section{Black Sea Journal of Engineering and Science}
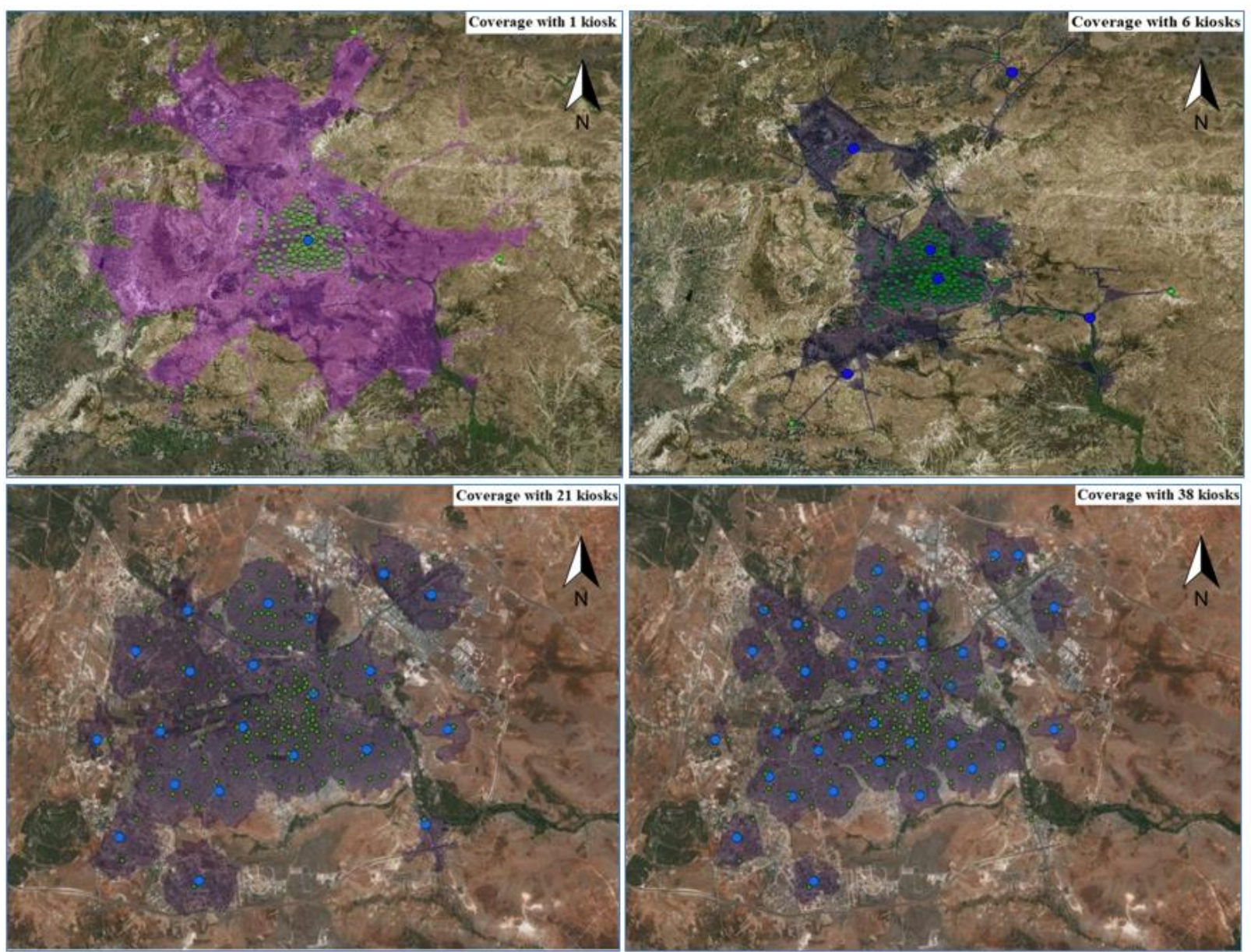

Legend - Kiosk $\bullet$ Neighborhood

Figure 5. Solutions of four different set covering instances

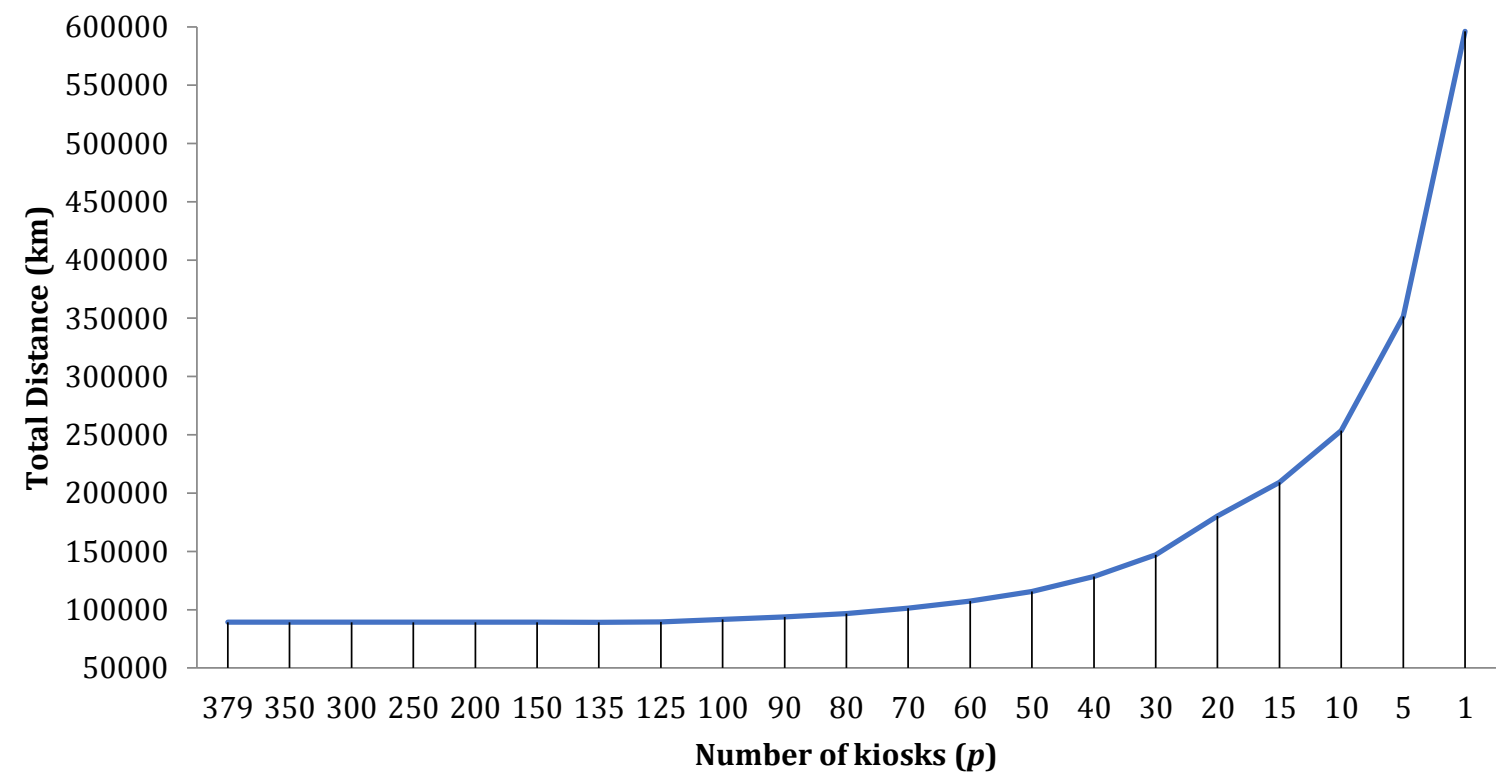

Figure 6. The results of P-median problem

The illustrations of four P-median cases are shown in Figure 7. Although all the passengers can reach a kiosk in four cases, it is clear that there is no a balanced distribution. For instance, in the case of $p=1$, while the total walking distance is $596 \mathrm{~km}$ between all passengers and $74^{\text {th }}$ kiosk, the maximum distance among 177 assignments to $74^{\text {th }}$ kiosk is $24 \mathrm{~km}$. a similar situation can be observed in the case of $p=135$. Most of the passengers can access a kiosk in a very short distance; only the three demand nodes become distanced from the nearest kiosks. 


\section{Black Sea Journal of Engineering and Science}

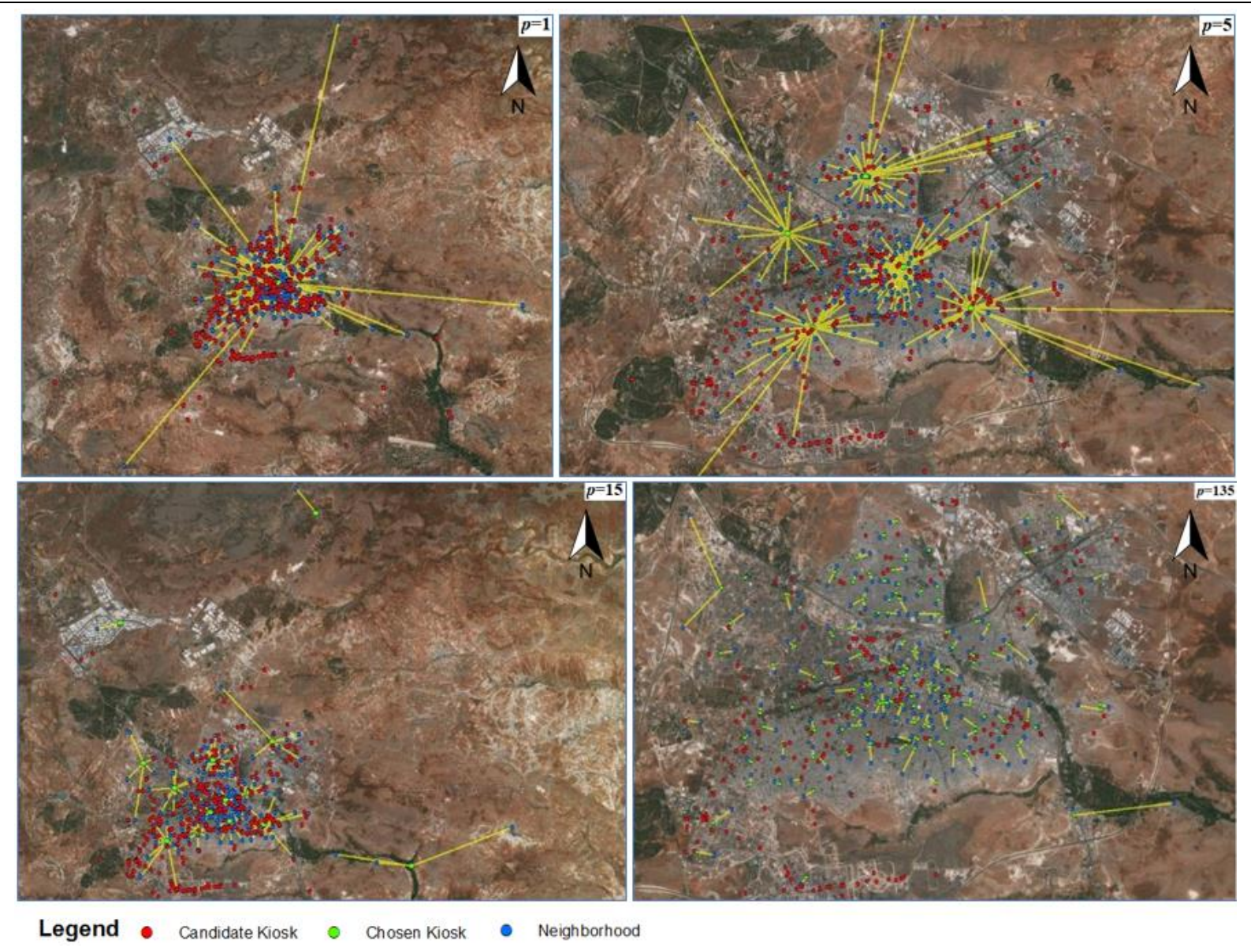

Figure 7. Solutions of four different P-median instances.

\section{Conclusion}

In this paper, current locations of transportation kiosks in Gaziantep are investigated to analyze accessibility to the passengers. To do so, firstly geographic information of 379 kiosks and 177 populations' nodes are determined using GIS. Secondly, set covering model to investigate the coverage and P-median model to investigate the required number of kiosks are applied. Computational experiments on the case study prove that less than 379 kiosks are enough for all the passengers however the spatial distribution of kiosks are not well-balanced.

For future studies, (i) a web-based GIS application should be developed, (ii) other location-allocation models such as P-center and maximal covering problems should be considered, and (iii) investigated area should be expanded. In this case, heuristics should be required to obtain a near optimal solution.

\section{Conflict of interest}

The authors declare that there is no conflict of interest.

\section{Acknowledgements}

The earlier version (as an abstract) of this paper was presented at the $7^{\text {th }}$ Business \& Management Conference in Budapest, Hungary, 5-8 June 2018.

\section{References}

Amoroso S, Caruso L, Cassata G, Maritano L. 2015. Optimal location for bike parking lots: The case study of Palermo. Ingegneria Ferroviaria, 70(7-8): 599-610.

Balabanov A, Stoilov T, Boneva Y. 2016. Linear-quadraticgaussian optimization of urban transportation network with application to Sofia traffic optimization. Cybernetics Inform Technol, 16(3): 165-184.

Beasley J. 1987. An algorithm for set covering problem. Eur J Operat Res, 31(1): 85-93.

Brette 0, Buhler T, Lazaric N, Marechal K. 2014. Reconsidering the nature and effects of habits in urban transportation behavior. J Instl Econ, 10(3): 399-426.

Cheng YH, Chang YH, Lu IJ. 2015. Urban transportation energy and carbon dioxide emission reduction strategies. Applied Energy, 157: 953-973.

Choi H, Nakagawa D, Matsunaka R, Oba T, Yoon J. 2013. Research on the causal relationship between urban density, travel behaviors, and transportation energy consumption by economic level. Int J Urban Sci, 17(3): 362-384.

Farahani RZ, Fallah S, Ruiz R, Hosseini S, Asgari N. 2018. OR models in urban service facility location: A critical review of applications and future developments. Eur J Operat Res. doi: 10.1016/j.ejor.2018.07.036.

Feng S, Hu B, Ma D, Wang D. 2016. Setting method of passenger site on inter-city expressway. J Harbin Instit Technol, 48(3): 71-76.

He D, Meng F, Wang MQ, He K. 2011. Impacts of urban transportation mode split on $\mathrm{CO}_{2}$ emissions in Jinan, China. Energies, 4(4): 685-699. 
Koryagin M. 2018. Urban planning: A game theory application for the travel demand management. Periodica Polytechnica Transport Engin, 46(4): 171-178.

Mete S, Cil ZA, Özceylan E. 2018. Location and coverage analysis of bike-sharing stations in university campus. Business Systems Res, 9(2): 80-95.

Mladenović N, Labbé M, Hansen P. 2003. Solving the p-center problem with tabu search and variable neighborhood search networks. Networks: An Inter J, 42(1): 48-64.

Murray AT. 2001. Strategic analysis of public transport coverage. Socio-Economic Planning Sciences, 35(3): 175-188.

$\mathrm{Pu}$ H, Ma CR. 2014. Optimization analysis on urban transportation network of Lanzhou. Applied Mech Mater, 641642: 685-689.

Teixeira JC, Antunes AP. 2008. A hierarchical location model for public facility planning. Eur J Operat Res, 185(1): 92-104.

Van Oudheusden DL, Ranjithan S, Singh KN. 1987. The design of bus route systems - An interactive location-allocation approach. Transport, 14(3): 253-270. 